\title{
Central treatment of different emulsion wastewaters by an integrated process of physicochemically enhanced ultrafiltration and anaerobic-aerobic biofilm reactor
}

\author{
Weijun Zhang, Ping Xiao, Dongsheng Wang* \\ State Key Laboratory of Environmental Aquatic Chemistry, Research Center for Eco-Environmental Sciences, Chinese Academy of Sciences, 18, Shuangqing Road, Beijing 100085, China
}

\section{H I G H L I G H T S}

- A novel integrated process for waste emulsions from different sources was developed.

- Combined chemical emulsion breaking and VSEP can efficiently improve membrane flux.

- Chemical demulsification pretreatment can improve oil removal efficiency by UF.

- UF permeate exhibited good biodegradability.

- More than $90 \%$ of COD in UF effluent was mineralized by $\mathrm{A} / \mathrm{O}$ biofilm system.

\section{A R T I C L E I N F O}

\section{Article history:}

Received 21 December 2013

Received in revised form 14 February 2014

Accepted 19 February 2014

Available online 28 February 2014

\section{Keywords:}

Anaerobic and aerobic biofilm system

Biodegradability

Chemical emulsion breaking

Emulsion wastewaters

Vibratory shear enhanced process (VSEP)
G R A P H I C A L A B S T R A C T

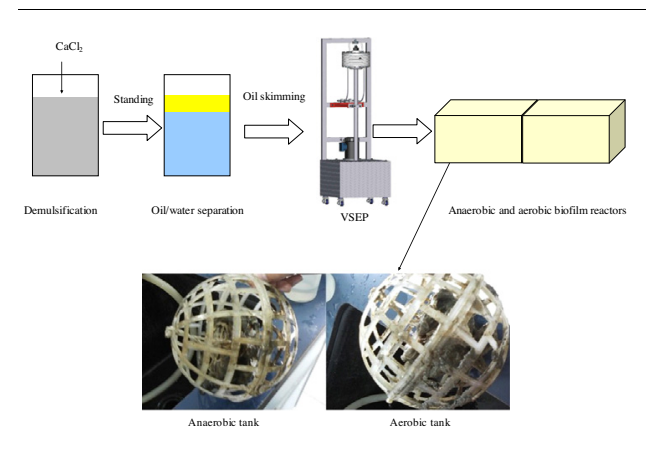

\begin{abstract}
A B S T R A C T
The feasibility of an integrated process of ultrafiltration (UF) enhanced by combined chemical emulsion breaking with vibratory shear and anaerobic/aerobic biofilm reactor for central treatment of different emulsion wastewaters was investigated. Firstly, it was found that calcium chloride exhibited better performance in oil removal than other inorganic salts. Chemical demulsification pretreatment could efficiently improve oil removal and membrane filtration in emulsion wastewater treatment by VSEP. According to aerobic batch bioassay, UF permeate exhibited good biodegradability and could be further treated with biological process. Additionally, pilot test indicated that anaerobic-aerobic biofilm exhibited an excellent ability against rise in organic loading and overall chemical oxygen demand (COD) removal efficiency of biological system was more than $93 \%$ of which $82 \%$ corresponded to the anaerobic process and $11 \%$ to the aerobic degradation. The final effluent of integrated process could meet the "water quality standards for discharge to municipal sewers" in China.
\end{abstract}

(c) 2014 Elsevier Ltd. All rights reserved.

\section{Introduction}

Metalworking fluids (MWFs) are widely used for cooling and lubricating during the machining process. Spent MWFs with high organic content cause serious contamination and rancid odor due

\footnotetext{
* Corresponding author. Tel./fax: +86 1062849138.

E-mail address: wgds@rcees.ac.cn (D. Wang).
}

to the presence of complex chemicals, biocides, etc., hence, their treatment and final disposal must be handled carefully (Cheng et al., 2005). In waste MWF treatment, physiochemical technologies are generally applied as pre-treatment to separate oil from water. Traditional separation processes such as gravity, flotation and skimming are not very efficient to remove oil droplets from water since oil has been chemically emulsified, thus chemical emulsion breaking is always used as a pretreatment step to destabilize the emulsion system and force oil to separate from 
water. The use of inorganic salt can reduce the repulsive force between the oil droplets; at the same time, it facilitates them to interact and coalesce, and therefore the drop size of oil droplet increases in the bulk (Karhu et al., 2014; Shin and Kim, 2001). In addition, ultrafiltration (UF) is also one of the most promising technologies for oil removal, thanks to the advantages of chemical additive free and high oil rejection (Belkacem et al., 1995). However, the permeate flux of traditional membrane separation decreases rapidly with time due to membrane fouling and concentration polarization. Therefore, several physicochemical methods have been developed to mitigate membrane fouling and enhance filtration such as adding reactive salts (Belkacem et al., 1995), coagulation/flocculation pretreatment (Zhong et al., 2003) and dynamic shear enhanced processes, i.e., rotating membranes and vibratory shear enhancing process (VSEP) (Ersahin et al., 2012; Jaffrin, 2008; Zhang et al., 2013). According to the report of Belkacem et al., the membrane flux was greatly enhanced by adding low dosage of inorganic salt. In addition, VSEP can efficiently prevent concentration polarization and membrane fouling in the process of emulsions filtration by producing high frequency of shear. Consequently, a high flux can be achieved at low feeding pressure, resulting in low energy consumption but high treatment capacity (Jaffrin, 2008; MoulaiMostefa et al., 2007, 2010). The large-scale industrial equipments of VSEP have been used for various oily wastewaters treatment.

Additionally, the UF permeate of various emulsion wastewaters were characterized of high organic content and complex composition. The wastewaters with high organic content are preferably treated in an anaerobic reactor due to its excellent ability against high organic loading, low energy consumption and low surplus sludge production (Frijters et al., 2006; Shi et al., 2014). The effluent produced by the anaerobic treatment always contains solubilized organic matter of low molecular weight (Ji et al., 2009). This is suitable for aerobic treatment, and subsequent post treatment using aerobic treatment is required to meet the effluent discharge standard (Chan et al., 2009; Mata-Alvarez et al., 2000). In addition, emulsion wastewater always contains complex chemicals and biocides which are resistant to biodegradation and might inhibit the microbial activity. Growth in biofilms renders the microbial cells to have several competitive advantages over planktonic growth such as a greater variation in population and less sensitivity to environmental factors such as temperature, $\mathrm{pH}$, and toxic substances (Chan et al., 2009; Sipma et al., 2010). This is attributed to substrate gradients and extracellular polymeric matrix which may result in a significant reduction of overall toxicity and inhibitory effect to microorganisms. Therefore, biochemical reactor filled with composite biocarriers showed a better performance against loading shock and stability of biological system (El-Shafai and Zahid, 2013; Murali et al., 2013).

In our previous study, it was found that some disperse oil droplets were too tiny to be rejected by UF (Zhang et al., 2013). Therefore, this work attempted to use combined chemical demulsification and VSEP to maximizing both membrane flux and oil removal in UF treatment of waste emulsions from different industrial sources. That is to say, the emulsion breaking process was applied as pretreatment step to reduce the organic loading and increase the floc size distribution of oil droplets, and then effluent was further treated by VSEP to remove the residual oil. Finally, the technical feasibility and process optimization of anaerobic/aerobic biofilm process for UF permeate treatment was also investigated.

\section{Methods}

\subsection{Materials}

The petroleum ether, potassium dichromate, sodium chloride $(\mathrm{NaCl})$, ferrous sulfate heptahydrate salt $\left(\mathrm{FeSO}_{4} \cdot 7 \mathrm{H}_{2} \mathrm{O}\right)$, calcium chloride $\left(\mathrm{CaCl}_{2}\right)$ were analytical grade reagents. Solid ferric chloride $\left(\mathrm{FeCl}_{3}\right)$, polymeric ferric sulfate (PFS) and polyaluminium chloride $(\mathrm{PACl})$ were industrial grade reagents and purchased from Beijing million water reagents plant.

\subsection{Wastewater sample}

The six oil-in-water $(\mathrm{O} / \mathrm{W})$ emulsions used in this study were obtained from different metal manufacturing processes. The characteristics of the emulsions are presented in Table 1.

\subsection{VSEP system}

The filtration module is depicted in Fig. 1. The shaft supporting the membrane module serves as the function of a torsion spring, which transmits oscillations created by an eccentric driving motor. The displacement amplitude and oscillation frequency of the equipment were fixed at $2 \mathrm{~cm}$ and $50 \mathrm{~Hz}$ respectively. The permeate from the membrane filtration passes through the permeate tubing which locates upon the spring under atmospheric pressure. The concentrated stream permeates through the "out" line. The return flow passes through the flow limiter and the control valve allowing the fine adjustment of outlet pressure. A "Y-trap" and bypass valve for adjusting the inlet pressure is equipped at the inlet and outlet of pump respectively. Meanwhile, the transmembrane pressure (TMP) is estimated as the mean value of the inlet and outlet pressure (Moulai-Mostefa et al., 2010; Zhang et al., 2013), and the inlet and outlet pressures were kept constant at 344.8 and $125 \mathrm{kPa}$. Membrane flux is measured in accordance with the volume of fluid within a certain period. Each run is stopped after reaching $80 \%$ permeate recovery. Membrane is made of hydrophilic polyethersulfone with $150 \mathrm{kDa}$ nominal cut-off, and the effective area is $1.54 \mathrm{~m}^{2}$. The detailed features of the membrane can be found in Table 2. Molecular weights of Dextran T2000 and T500 are $2000 \mathrm{kDa}$ and $500 \mathrm{kDa}$.

\subsection{Demulsification process for membrane filtration enhancement}

Sample 6 with highest organic concentration was selected as experimental wastewater in this section. The chemical emulsion breaking efficiency of $\mathrm{NaCl}, \mathrm{FeSO}_{4} \cdot 7 \mathrm{H}_{2} \mathrm{O}, \mathrm{CaCl}_{2}, \mathrm{FeCl}_{3}$, PFS and PACl were compared in this study. A $1000 \mathrm{~mL}$ of wastewater was added in an $800 \mathrm{~mL}$ beaker. Then, the demulsifiers at different doses were added in the beaker under vigorous stirring using a magnetic stirrer. After standing for a period of time, a separating funnel was used to separate the floating oil from water. The COD and oil content of the water phase was determined.

\subsubsection{Biological treatment of UF permeate}

2.4.1.1. Biodegradability assessment. Aerobic batch bioassay was adopted to evaluate the biodegradability of UF permeate. This approach has been described in detail elsewhere (Kitis et al., 1999). Briefly, the bioassays were conducted by adding $300 \mathrm{~mL}$ of sample into a $500 \mathrm{~mL}$ of Erlenmeyer flask. The water sample was provided with microbial seed from aeration tank of Quyang wastewater treatment plant (WWTP) in Shanghai city, micro-and macronutrients and phosphate buffering. Concentration and dosage of activated sludge were $15 \mathrm{~g} / \mathrm{L}$ and $1 \mathrm{ml} / \mathrm{L}$ respectively. Batch bioassays were also conducted on the permeate at an initial COD concentration of $1000 \mathrm{mg} / \mathrm{L}$. The supernatant was filtrated through $0.45 \mu \mathrm{m}$ membrane filter before COD analysis. Sample was considered biodegradable when the dissolved COD removal efficiency was over $70 \%$ after biooxidation for 30 days.

2.4.1.2. Anaerobic/aerobic $(A / O)$ process for permeate UF treatment. The biological oxidation system is composed by an anaerobic tank $(30 \mathrm{~L})$, 
Table 1

Water quality of the waste emulsions.

\begin{tabular}{llcccc}
\hline Sample & $\mathrm{pH}$ & $\mathrm{COD}(\mathrm{mg} / \mathrm{L})$ & Oil content $(\mathrm{mg} / \mathrm{L})$ & SS $(\mathrm{mg} / \mathrm{L})$ & Conductivity $(\mathrm{ms} / \mathrm{cm})$ \\
\hline 1 & 7.3 & 53,900 & 26805 & 4439 & 0.21 \\
2 & 6.8 & 69,200 & 1590 & 8215 & 0.54 \\
3 & 7.3 & 31,100 & 976 & 2075 & 1.73 \\
4 & 8.0 & 156,800 & 3258 & 4575 & 2.73 \\
5 & 8.4 & 55,400 & 876 & 655 & 1.43 \\
6 & 9.2 & 235,300 & 30584 & 3085 & 2.56 \\
\hline
\end{tabular}

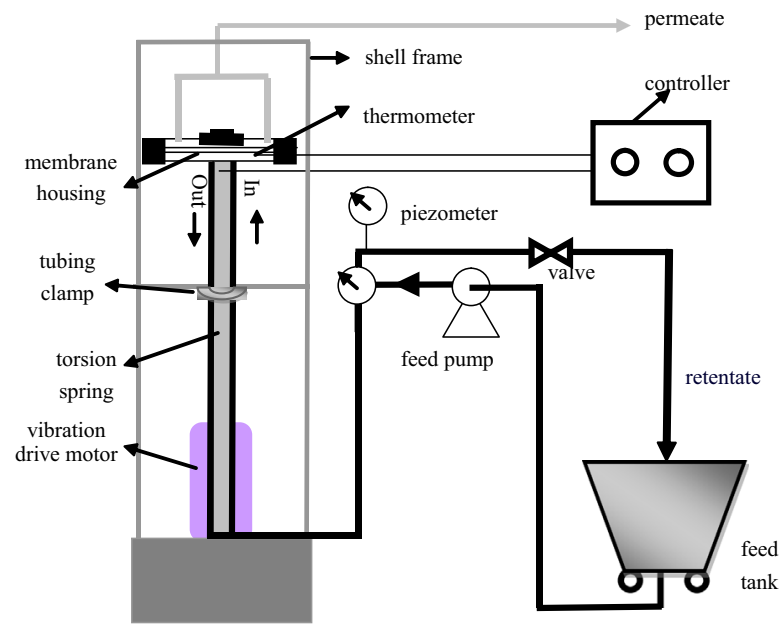

Fig. 1. VSEP filtration module.

Table 2

Technical data of UF membrane $\left(70 \mathrm{kPa}, 20^{\circ} \mathrm{C}\right.$, stirred cell: $\left.700 \mathrm{rpm}\right)$.

\begin{tabular}{|c|c|c|c|}
\hline \multicolumn{2}{|c|}{ Test solute rejection (\%) } & \multicolumn{2}{|c|}{ Pure water flux $\left(\mathrm{L} \mathrm{m}^{-2} \mathrm{~h}^{-1}\right)$} \\
\hline $\begin{array}{l}\text { Dextran T2000 } \\
(1 \%)\end{array}$ & $\begin{array}{l}\text { Dextran T500 } \\
(1 \%)\end{array}$ & $70 \mathrm{kPa}$ & $300 \mathrm{kPa}$ \\
\hline $87-92$ & $50-60$ & $300-600$ & $1200-2100$ \\
\hline
\end{tabular}

an aerobic tank $(30 \mathrm{~L})$ and a settling tank $(5 \mathrm{~L})$. All the tanks were made in polypropylene. Both of bio-tanks were filled with composite biocarrier to enhance the stability of biological system. Outer structure of biocarrier is two net-shaped spheres made of polypropylene, while inner structure is plastic ring loading the vinylon silk. Bioreactors were inoculated by activated sludge from Quyang WWTP. Additionally, the aerobic tank was also equipped with a dissolved oxygen detector and air is supplied by a blower (2PB810H17; ceramic air diffuser) for maintaining the oxygen content in the aerobic tank at about $3 \mathrm{mg} / \mathrm{L}$.

\subsection{Analytical methods}

Oil concentrations in the feed and permeate solutions were analyzed using petroleum ether extraction followed by gravimetric method according to the National Standard of China CJ/T51-2004, while COD was measured using the potassium dichromate method based on the National Standard of China GB 119 14-89. Total nitrogen (TN) and Total phosphate (TP) were also determined with standard methods. $\mathrm{pH}$ was measured by $\mathrm{pH}$ meter (pHS-3C, Shanghai, China). Content of suspended solid (SS) and conductivity were determined by gravimetric and electrometric methods respectively.

\section{Results and discussion}

\subsection{Emulsion wastewater treatment by VSEP}

\subsubsection{COD and oil removal efficiency of VSEP}

The effects of VSEP on removal of COD, oil and SS were presented in Table 3. Due to the different sources and composition of water sample, the COD removal efficiency was different from $36 \%$ to $95 \%$. However, the more than $97 \%$ of oil was removed by UF treatment from all samples. In addition, SS was completely rejected. The COD concentration of UF permeate was in range from 2560 to $54,500 \mathrm{mg} / \mathrm{L}$, since a certain amount of disperse oil and organic additives of low molecular weight could not be rejected.

\subsubsection{Change in membrane and sample temperature during VSEP treatment}

Fig. 2 demonstrated the changes of membrane flux and temperature of the samples during filtration. Because of the frictional heating contributed by high-speed shear force of vibrating membrane, the increase in the temperature of each sample was almost linear to time. The flux was very stable during filtration processing, indicating that the VSEP process could effectively reduce the concentration and polarization via high shear rates. However, Moulai-Mostefa and coworkers reported that the membrane flux decreased with time due to the increase of oil concentration at constant temperature and pressure (Moulai-Mostefa et al., 2007, 2010). The results of flux observed in the study could be explained by the increase of the sample temperature in practical application. It is well known that the higher temperature can decrease viscosity of water, and consequently, increase the permeability through membrane. The increased temperature could counteract the flux decline caused by the increase of oil concentration. Therefore, the membrane flux can be effectively enhanced by increasing the temperature of wastewater. Additionally, it should be noted that no obvious relationship could be found between membrane flux and content of SS, oil and COD in wastewater. This result revealed that membrane performance may mainly be decided by organic composition of wastewater rather than concentration.

\subsection{Enhanced membrane filtration by chemical precoagulation}

\subsubsection{Efficiency of different demulsifiers on $C O D$ and oil removal}

In order to select the optimum demulsifier for emulsion wastewaters treatment, batch tests were conducted with different

Table 3

Effect of VSEP on treatment of waste emulsions from different industrial sources.

\begin{tabular}{|c|c|c|c|c|c|c|}
\hline \multirow[t]{2}{*}{ Sample } & \multicolumn{3}{|c|}{ Raw wastewater (mg/L) } & \multicolumn{3}{|c|}{ Permeate $(\mathrm{mg} / \mathrm{L})$} \\
\hline & COD & Oil & SS & COD & Oil & SS \\
\hline 1 & 53,900 & 26,805 & 4439 & 2560 & 279 & 0 \\
\hline 2 & 69,200 & 21,485 & 8215 & 4530 & 530 & 0 \\
\hline 3 & 31,100 & 15,485 & 2075 & 7010 & 334 & 0 \\
\hline 4 & 156,800 & 19,280 & 4575 & 7380 & 256 & 0 \\
\hline 5 & 55,400 & 12,876 & 655 & 35,000 & 92 & 0 \\
\hline 6 & 235,300 & 153,883 & 3085 & 54,500 & 505 & 0 \\
\hline
\end{tabular}



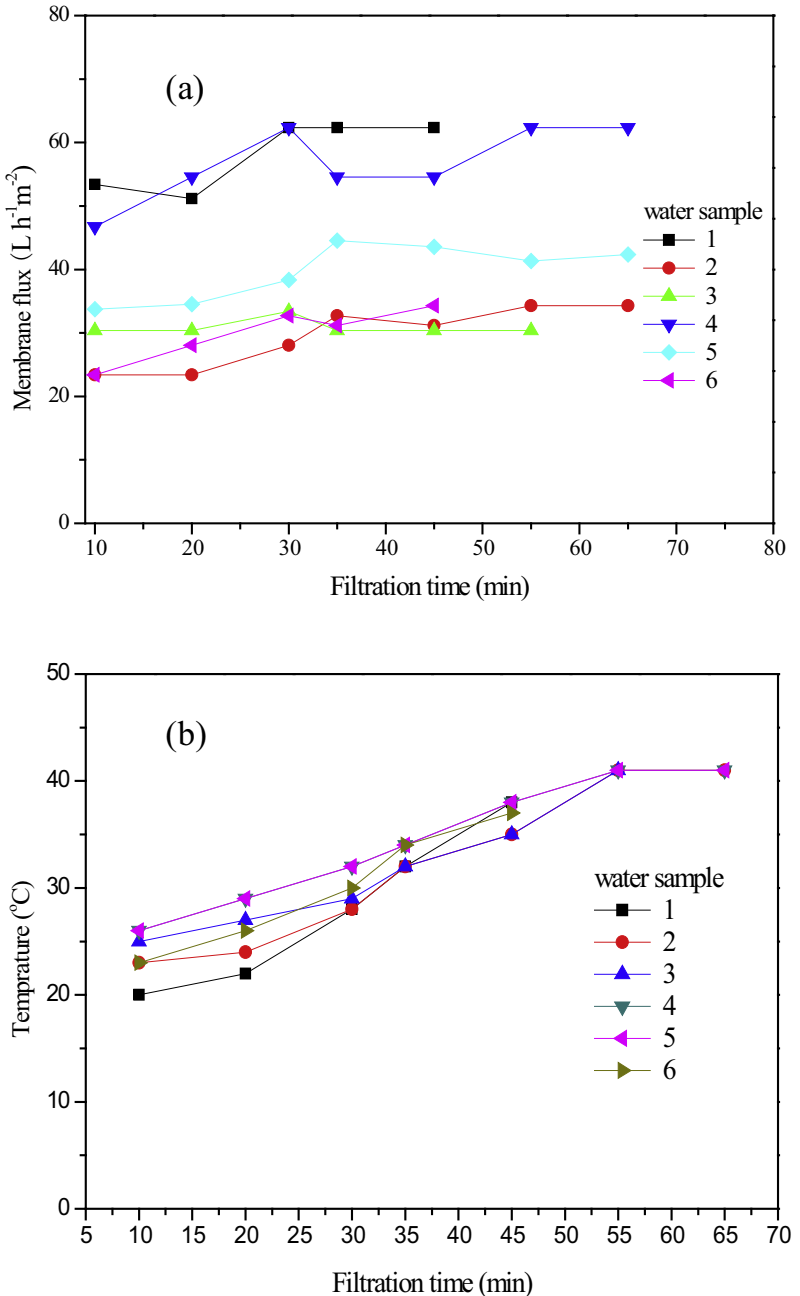

Fig. 2. Change in membrane flux (a) and temperature (b) of emulsions during filtration by VSEP.

inorganic salt flocculants. The selection was based on oil contents and COD values of solution after addition. As depicted in Fig. 3, the oil contents and COD values were decreased dramatically by the addition of various demulsifiers. $\mathrm{CaCl}_{2}$ and $\mathrm{NaCl}$ performed better in oil and COD removal than hydrolyzed inorganic coagulants. This might be attributable to the fact that $\mathrm{CaCl}_{2}$ and $\mathrm{NaCl}$ were mainly in the form of solutions after addition, they can make better contact with dissolved emulsified oil than inorganic coagulants which would undergo rapid hydrolysis, aggregation, precipitation, and ultimately converted to insoluble precipitates. These hydrolyzed products could only partially interact with dissolved emulsions, thus making oil/water separation less efficient. The optimal dosage of $\mathrm{CaCl}_{2}$ was around $2 \mathrm{~g} / \mathrm{L}$, and organic removal efficiency was not enhanced with further increase in its dosages.

Fig. 4 shows the change in demulsification efficiency withholding time after stirring. It can be seen that the removal rate of oil is relatively faster within $100 \mathrm{~min}$ and the rate decreased after this time. Equilibrium is almost reached in $3 \mathrm{~h}$, at the same time, a layer of oil was separated out and floated on top of emulsion system. As a result, the oil content was reduced to $15 \%$ of the initial value.

\subsubsection{Effect of chemical demulsification on VSEP performance}

Since the effluent of chemical emulsion breaking treatment still contained high concentration oil, the VSEP was used to reject the residual oil. The floating oil layer was skimmed off prior to being
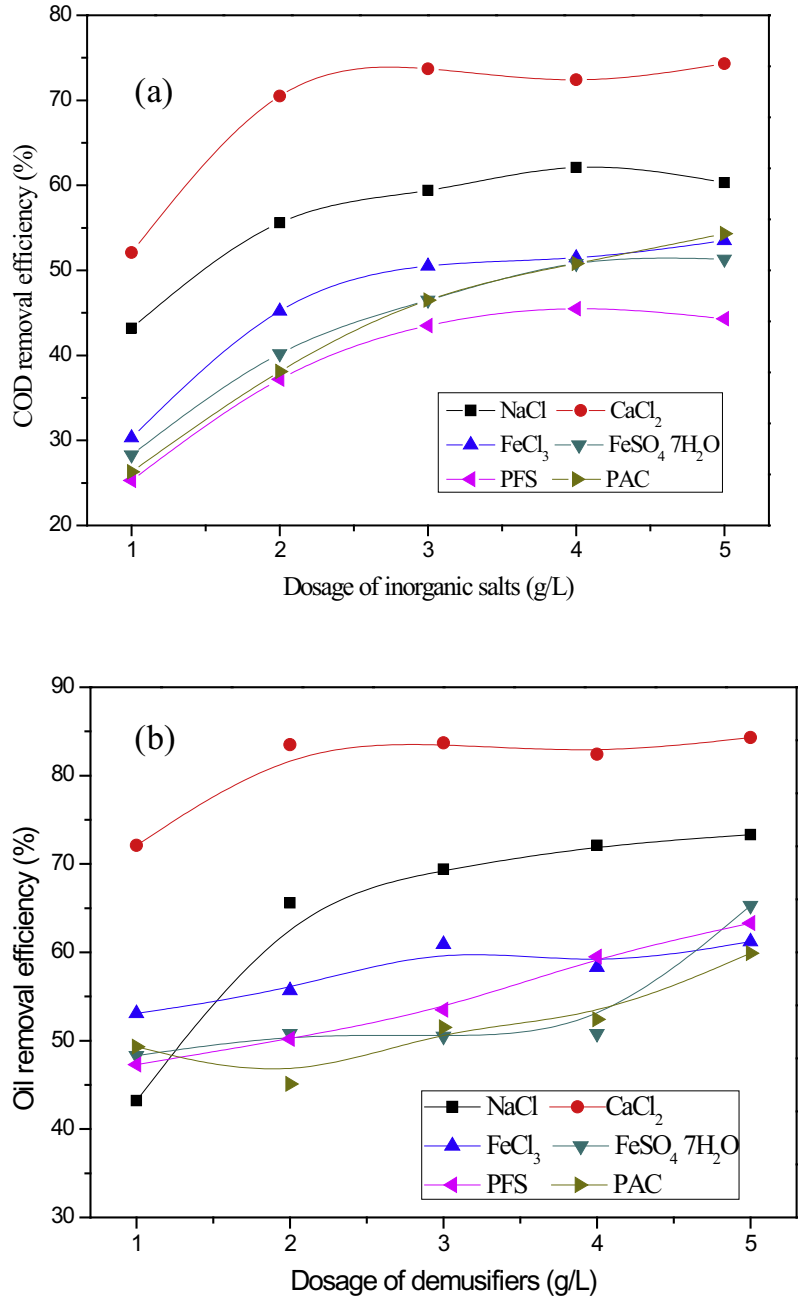

Fig. 3. Performance of different demulsifiers in COD (a) and oil (b) removal efficiency (holding time was $4 \mathrm{~h}$ ).

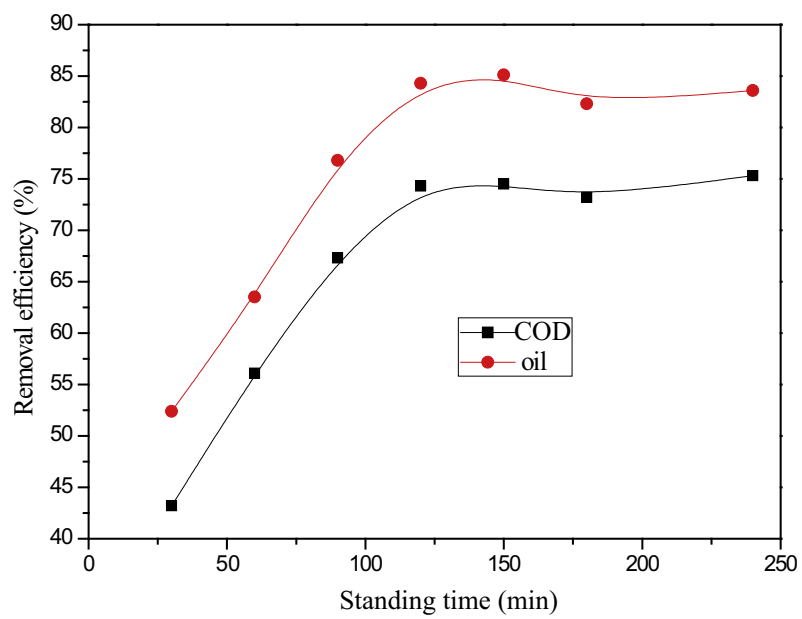

Fig. 4. Effect of standing time on $\mathrm{COD}$ and oil removal $\left(\mathrm{CaCl}_{2}\right.$ as demusifier).

treated by membrane. As depicted in Fig. 5(a), the average membrane flux was significantly improved by using chemical demulsification pretreatment, thus leading to enhancement of membrane filtration capacity and reduction of equipment investment. This was because the disperse emulsified oil droplets 

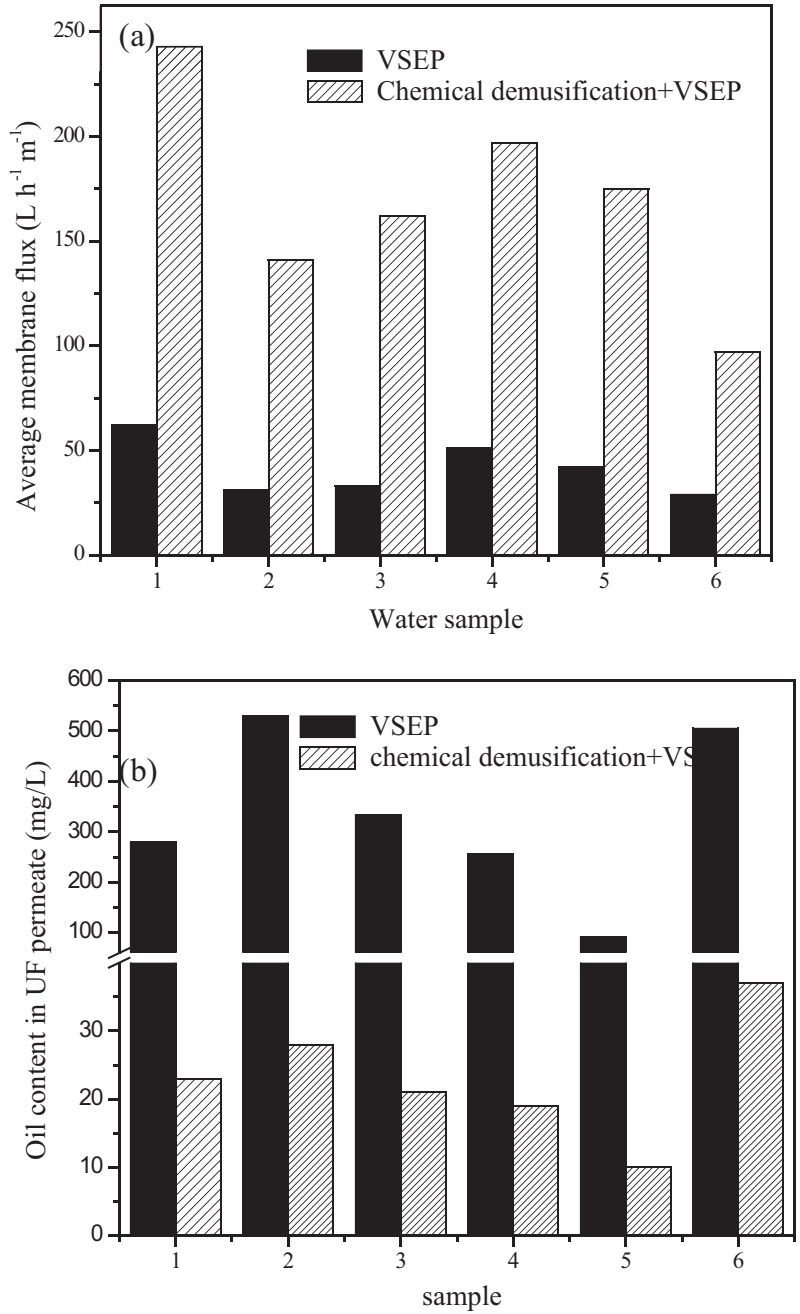

Fig. 5. Effect on chemical demulsification on (a) membrane flux and (b) COD removal efficiency $\left(\mathrm{CaCl}_{2}\right.$ dosage was $\left.2 \mathrm{~g} / \mathrm{L}\right)$.

aggregated after chemical emulsion breaking, as a result, the extent of pore plugging was reduced and the void of sedimentation layer on membrane surface was enhanced (Zhong et al., 2003). In addition, Fig. 5(b) showed combined chemical demulsification and VSEP exhibited better performance in oil removal in comparison to VSEP alone. This observation was attributable to increase in size distribution of emulsified oil droplets caused by destabilization (Belkacem et al., 1995).

\subsection{Biotreatment of UF permeate}

\subsubsection{Biodegradability analysis of UF permeate}

The results of aerobic batch tests were given in Fig. 6. For all samples, 70\% biodegradability was attained after $90 \mathrm{~h}$ of biotreatment, indicating that UF permeate exhibited good biodegradability and could be further treated with biological process. Biooxidation process could be divided into three different stages. The first stage is fast degradation stage, where the microorganisms grows rapidly by consuming easily biodegradable dissolved organic carbon, about $50 \%$ of dissolved COD was reduced after $100 \mathrm{~h}$. This result was consistent with the biochemical oxygen demand (BOD) analysis (Table S1 in Supporting Information (SI)). In this second stage (100-250 h), bioxidation rate became slower as readily available food is consumed, and the activated sludge started to utilize the organic substances with medium degradability, accounting for

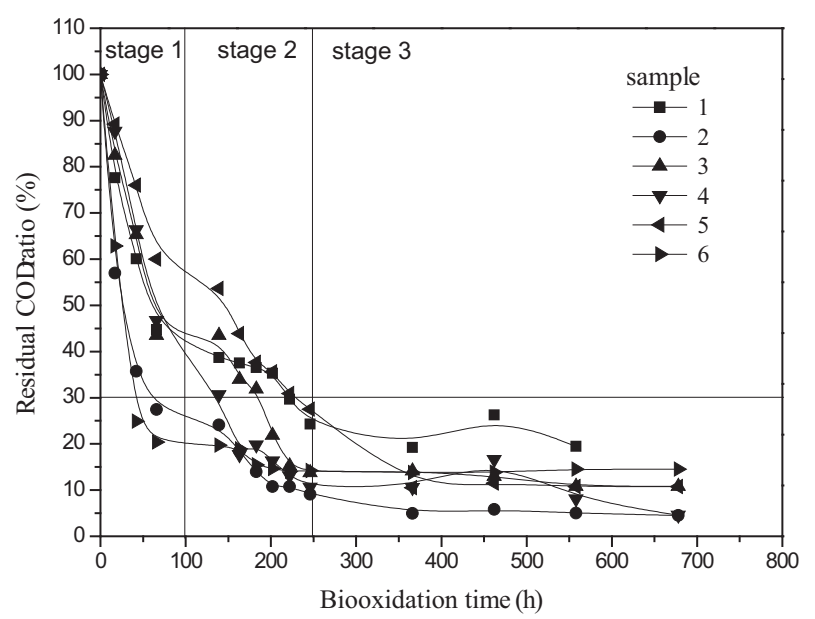

Fig. 6. Change of dissolved COD in permeate with biooxidation time.

$30-40 \%$ of total organic content. Finally, biooxidation entered endogenous respiration period, $10-20 \%$ of organic matter might be resistant to biodegradation and still remained in water.

\subsubsection{Optimization of organic loading of $A / O$ process}

The two biochemical tanks were inoculated with $1 \mathrm{~L}$ of concentrated activated sludge from the aerobic tank of WWTP respectively. Recirculation was then maintained between the settling tank and bioreactors for several days in order to ensure fixation of the sludge on biocarriers. The effluent COD concentration was measured daily. Initially, nutrient solution prepared with glucose, peptone and inorganic salts (nitrogen, phosphate) was added to the immobilized bioreactor (IBR) in order to nourish and increase the biomass concentration fixed on the bio-carriers. COD, TN and TP of nutrient solution were $2500 \mathrm{mg} / \mathrm{L}, 125 \mathrm{mg} / \mathrm{L}$ and $25 \mathrm{mg} / \mathrm{L}$ respectively. The photo of activated sludge growed in the inert carriers was given in Figure S1 of SI, revealing that proper microorganisms fixation was finished.

As shown in Table 4, the biotreatment of UF permeate was divided into domestication period, adjustment period and normal operation stage. It should be pointed out that several UF permeate was mixed together prior to biotreatment. And then UF effluent was transferred to a conditioning tank, where the $\mathrm{pH}$ and ratio of COD:N:P was adjusted to 8 and 100:5:1 (optimal ratio for bacteria growth) respectively. In the first stage, mixed permeate with low organic content $(\mathrm{COD}=2000-3000 \mathrm{mg} / \mathrm{L}$ ) was fed into the biological system for 28 days, and the specific volumetric organic load of the two tanks always remained around $0.85-0.9 \mathrm{~kg} \mathrm{COD} \mathrm{m}^{-3} \mathrm{~d}^{-1}$ and $0.2-0.23 \mathrm{~kg} \mathrm{COD} \mathrm{m}^{-3} \mathrm{~d}^{-1}$ respectively. It was found that anaerobic tank performed well in organic removal from the beginning, $75-80 \%$ of COD was reduced. Besides, the COD degradation was not observed initially, but it was enhanced with time, finally in aerobic treatment contributed to $50 \%$ reduction of COD. In the second stage (day 29-69), influent COD of anaerobic tank was increased to $4300-6500 \mathrm{mg} / \mathrm{L}$, at the same time specific volumetric organic load of anaerobic tank increased from 1.14 to $2.23 \mathrm{~kg} \mathrm{COD} \mathrm{m}^{-3} \mathrm{~d}^{-1}$. It can be seen that the effluent COD in anaerobic and aerobic tank rose from 486 to $1830 \mathrm{mg} / \mathrm{L}$ and $399-780 \mathrm{mg} / \mathrm{L}$ respectively. The increase in outlet COD could be attributed to two reasons. The biological system reached the limit of their capacity and, therefore, outlet DOC rose (Oller et al., 2007). Besides, 10-20\% of COD was resistant to biooxidation according to aerobic batch bioassay, the more concentrated inlet contained more non-biodegradable substances. Finally, from day 70 to 94 , the inlet COD was increased to $8500-9100 \mathrm{mg} / \mathrm{L}$, correspondingly, specific volumetric organic 
Table 4

Operating situation of anaerobic and aerobic biofilm process.

\begin{tabular}{|c|c|c|c|c|c|}
\hline \multirow[t]{2}{*}{ Operating stage } & \multirow{2}{*}{$\begin{array}{l}\text { Influent } \\
\text { COD (mg/L) }\end{array}$} & \multicolumn{2}{|l|}{ Anaerobic tank } & \multicolumn{2}{|l|}{ Aerobic tank } \\
\hline & & Organic loading $\left(\mathrm{kgCOD} \mathrm{m}^{-3} \mathrm{~d}^{-1}\right)$ & Effluent COD (mg/L) & Organic loading $\left(\mathrm{kgCOD} \mathrm{m}^{-3} \mathrm{~d}^{-1}\right)$ & Effluent COD $(\mathrm{mg} / \mathrm{L})$ \\
\hline \multirow[t]{7}{*}{ Domestication period } & 2640 & 0.88 & 658 & 0.22 & 563 \\
\hline & 2655 & 0.89 & 556 & 0.23 & 585 \\
\hline & 2565 & 0.84 & 582 & 0.25 & 476 \\
\hline & 2180 & 0.86 & 642 & 0.21 & 405 \\
\hline & 2640 & 0.88 & 658 & 0.22 & 353 \\
\hline & 2655 & 0.89 & 556 & 0.23 & 395 \\
\hline & 3115 & 0.90 & 540 & 0.20 & 332 \\
\hline \multirow[t]{10}{*}{ Adjustment period } & 4555 & 1.14 & 486 & 0.20 & 399 \\
\hline & 4375 & 1.42 & 595 & 0.23 & 436 \\
\hline & 6740 & 1.69 & 1209 & 0.22 & 415 \\
\hline & 5370 & 1.79 & 1405 & 0.25 & 527 \\
\hline & 6160 & 1.54 & 1427 & 0.21 & 453 \\
\hline & 7090 & 1.77 & 1718 & 0.23 & 500 \\
\hline & 4320 & 1.73 & 1670 & 0.25 & 575 \\
\hline & 5300 & 2.05 & 1535 & 0.27 & 561 \\
\hline & 5000 & 2.14 & 1595 & 0.65 & 625 \\
\hline & 6450 & 2.23 & 1830 & 0.56 & 780 \\
\hline \multirow[t]{6}{*}{ Stable period } & 10,900 & 2.73 & 842 & 0.23 & 800 \\
\hline & 10,470 & 2.18 & 1059 & 0.25 & 848 \\
\hline & 8760 & 2.09 & 1010 & 0.29 & 827 \\
\hline & 9080 & 2.19 & 1045 & 0.23 & 829 \\
\hline & 8090 & 2.02 & 981 & 0.26 & 825 \\
\hline & 8500 & 2.13 & 1530 & 0.20 & 725 \\
\hline
\end{tabular}

load of the anaerobic tank rose to 2.73 to $2.89 \mathrm{~kg} \mathrm{COD} \mathrm{m}^{-3} \mathrm{~d}^{-1}$. The outlet of two tanks remained stable at $1400-1700$ and $500-600 \mathrm{mg} / \mathrm{L}$, overall COD removal efficiency of the A/O process was more than $93 \%$ of which $82 \%$ corresponded to the anaerobic treatment and $11 \%$ to the aerobic process. The COD concentration of final effluent could meet the "water quality standards for discharge to municipal sewers in China. Furthermore, the concentration of TN and TP in biological process was presented in Figure S2 of SI. Initially, the TP content in UF permeate was less than $2 \mathrm{mg} / \mathrm{L}$, but TP in two bioreactors was about $40 \mathrm{mg} / \mathrm{L}$ and $10 \mathrm{mg} / \mathrm{L}$ respectively. This observation was attributed to phosphate release from fresh activated sludge under anaerobic condition. Then, the phosphorus concentration in anaerobic tank and aerobic tank reduced to $10 \mathrm{mg} / \mathrm{L}$ and $5 \mathrm{mg} / \mathrm{L}$ before entering into wastewater feeding stage, but the TP concentration in final effluent was remained stable at around $1 \mathrm{mg} / \mathrm{L}$. The result demonstrated that growth of bacteria consumed a large amount of phosphate in biofilm formation stage.

\section{Conclusion}

The technical feasibility of an integrated process of chemical emulsion breaking, VSEP and anaerobic-aerobic biofilm for central treatment of various emulsion wastewaters was investigated. $\mathrm{CaCl}_{2}$ exhibited the best performance in oil removal. The membrane flux and oil removal efficiency were effectively enhanced by combined chemical demulsification and VSEP. Furthermore, overall COD removal efficiency of the anaerobic/aerobic biofilm system was over $93 \%$ of which $82 \%$ corresponded to the anaerobic process of PAC and $11 \%$ to the aerobic oxidation. This study provides a solution to treatment of emulsion wastewaters with high organic content from different industrial sources.

\section{Acknowledgements}

This research was funded by the Beijing Municipal Science and Technology Projects under Z131109002813040. The authors are very grateful to technical support from the Research Center for Eco-Environmental Sciences, Chinese Academy of Sciences.

\section{Appendix A. Supplementary data}

Supplementary data associated with this article can be found, in the online version, at http://dx.doi.org/10.1016/j.biortech.2014. 02.067 .

\section{References}

Belkacem, M., Matamoros, H., Cabassud, C., Aurelle, Y., Cotteret, J., 1995. New results in metal working wastewater treatment using membrane technology. J. Membr. Sci. 106 (3), 195-205.

Chan, Y.J., Chong, M.F., Law, C.L., Hassell, D., 2009. A review on anaerobic-aerobic treatment of industrial and municipal wastewater. Chem. Eng. J. 155 (1), 1-18.

Cheng, C., Phipps, D., Alkhaddar, R.M., 2005. Treatment of spent metalworking fluids. Water Res, 39 (17), 4051-4063.

El-Shafai, S.A., Zahid, W.M., 2013. Performance of aerated submerged biofilm reactor packed with local scoria for carbon and nitrogen removal from municipal wastewater. Bioresour. Technol. 143, 476-482.

Ersahin, M.E., Ozgun, H., Dereli, R.K., Ozturk, I., Roest, K., van Lier, J.B., 2012. A review on dynamic membrane filtration: Materials, applications and future perspectives. Bioresour. Technol. 122, 196-206.

Frijters, C., Vos, R., Scheffer, G., Mulder, R., 2006. Decolorizing and detoxifying textile wastewater, containing both soluble and insoluble dyes, in a full scale combined anaerobic/aerobic system. Water Res. 40 (6), 1249-1257.

Jaffrin, M.Y., 2008. Dynamic shear-enhanced membrane filtration: a review of rotating disks, rotating membranes and vibrating systems. J. Membr. Sci. 324 (1), 7-25.

Ji, G., Sun, T., Ni, J., Tong, J., 2009. Anaerobic baffled reactor (ABR) for treating heavy oil produced water with high concentrations of salt and poor nutrient. Bioresour. Technol. 100 (3), 1108-1114.

Karhu, M., Leiviskä, T., Tanskanen, J., 2014. Enhanced DAF in breaking up oil-inwater emulsions. Sep. Purif. Technol. 122, 231-241.

Kitis, M., Adams, C.D., Daigger, G., 1999. The effects of Fenton's reagent pretreatment on the biodegradability of nonionic surfactants. Water Res. 33 (11), 2561-2568.

Mata-Alvarez, J., Mace, S., Llabres, P., 2000. Anaerobic digestion of organic solid wastes. An overview of research achievements and perspectives. Bioresour. Technol. 74 (1), 3-16.

Moulai-Mostefa, N., Akoum, O., Nedjihoui, M., Ding, L., Jaffrin, M., 2007. Comparison between rotating disk and vibratory membranes in the ultrafiltration of oil-inwater emulsions. Desalination 206 (1), 494-498.

Moulai-Mostefa, N., Frappart, M., Akoum, O., Ding, L., Jaffrin, M.Y., 2010. Separation of water from metal working emulsions by ultrafiltration using vibratory membranes. J. Hazard. Mater. 177 (1), 978-982.

Murali, V., Ong, S.-A., Ho, L.-N., Wong, Y.-S., 2013. Evaluation of integrated anaerobic-aerobic biofilm reactor for degradation of azo dye Methyl Orange. Bioresour. Technol. 143, 104-111.

Oller, I., Malato, S., Sánchez-Pérez, J., Maldonado, M., Gernjak, W., Pérez-Estrada, L., Muñoz, J., Ramos, C., Pulgarín, C., 2007. Pre-industrial-scale combined solar 
photo-Fenton and immobilized biomass activated-sludge biotreatment. Ind. Eng. Chem. Res. 46 (23), 7467-7475.

Shi, X., Lefebvre, O., Ng, K.K., Ng, H.Y., 2014. Sequential anaerobic-aerobic treatment of pharmaceutical wastewater with high salinity. Bioresour. Technol. 153, 7986.

Shin, S.H., Kim, D.S., 2001. Studies on the interfacial characterization of O/W emulsion for the optimization of its treatment. Environ. Sci. Technol. 35 (14), 3040-3047.

Sipma, J., Osuna, M.B., Emanuelsson, M.A., Castro, P.M., 2010. Biotreatment of industrial wastewaters under transient-state conditions: process stability with fluctuations of organic load, substrates, toxicants, and environmental parameters. Crit. Rev. Environ. Sci. Technol. 40 (2), 147-197.

Zhang, W., Zhang, M., Xiao, F., Fang, L., Wang, D., 2013. Pretreatment of high strength waste emulsions by combined vibratory shear enhanced process with Fenton oxidation. Int. J. Environ. Sci. Technol. http://dx.doi.org/10.1007/ s13762-013-0217-0.

Zhong, J., Sun, X., Wang, C., 2003. Treatment of oily wastewater produced from refinery processes using flocculation and ceramic membrane filtration. Sep. Purif. Technol. 32 (1), 93-98. 